\title{
Effect of Glycyrrhiza glabra extract and aerobic exercise on the attitude of postmenopausal women to menopause
}

\author{
Parvaneh Asgari ${ }^{1}$, Fatemeh Bahramnezhad ${ }^{2 *}$, Mohammad Golitaleb ${ }^{1}$, Fatemeh Salehi ${ }^{1}$, \\ Razieh Mokhtari ${ }^{1}$, Fatemeh Rafiei ${ }^{3}$
}

1. Department of Nursing, Faculty of Nursing and Midwifery, Arak University of Medical Sciences, Arak , Iran

2. Department of Nursing, Faculty of Nursing and Midwifery, Tehran University of Medical Sciences, Tehran, Iran

3. Thyroid Disorders Research Center, Arak University of Medical Sciences, Arak, Iran

*Corresponding author:Tel: +98 2166927171 Fax: +98 2166904252

Address: Department of Nursing, Faculty of Nursing and Midwifery, Tehran University of Medical Sciences, Tehran, Iran

E-mail: bahramnezhad@ @razi.tums.ac.ir

Received; 2016/03/7 revised; 2016/07/15 accepted; 2016/11/9

\section{Abstract}

Introduction: Menopause is associated with complications that can affect women's attitudes. Women's attitudes toward menopause can help to improve their performance and reduce the severity of its complications. The aim of this study was to evaluate the effect of Glycyrrhiza glabra (G. glabra) plant and exercise on the attitude of menopausal women.

Materials and methods: This clinical experimental fourth group was conducted between October and March 2015 in Arak, Iran. 120 menopausal women were randomly selected and divided into four groups each containing 30 women. The first group had three G. glabra tablets daily for one month, the second group had a regular exercise program three times a week for 30-45 minutes for one month and the third group simultaneously took G. glabra like Group1 and followed exercise programs like Group 2 and the fourth group received no intervention. Before and one month after the intervention attitudes of women were compared with a researcher-made questionnaire. ANOVA, Chi-square and Paired tests were used to analysis the data.

Results: The results showed no significant difference between four groups in demographic characteristic. ANOVA results showed no significant difference between four groups in the attitude score of women before the intervention $(\mathrm{P}=0.937)$, but after the intervention there were significant differences between the groups $(\mathrm{P}=0.0001)$.

Conclusion: According to the results, G. glabra consumption and exercise program were effective in controlling the symptoms of menopause attitude of menopausal woman. Therefore, it may proposed as one of the main strategies for health and education interventions.

Keywords: Glycyrrhiza glabra, Exercise, Attitude, Menopause

\section{Introduction}

Physical and psychological problems caused by menopause affect women's attitude and attention to self-care and sense of femininity. This shift of attitude is caused by many reasons including: physical and psychological complications such as severe hot flashes, increased blood pressure, fatigue, erosion of ovaries, osteoporosis, urinary incontinence, depression and anxiety, concern about the role of women's femininity and sexuality (1). Mitigation and treatment of these 
complications can significantly change women's attitudes toward menopause (2). Change of women's attitudes, in addition to self-care, creates many problems for the spouse, children, community and health system (3). Problems such as reduction of estrogen, vaginal dryness and lack of attention to personal hygiene caused by physical and psychological complications may also affect the relationships and marriages of couples. Frequent hospitalizations due to bone fractures caused by osteoporosis, hot flashes and also create many problems for the health system (4).

Various strategies such as education, hormone therapy, regular aerobic and anaerobic exercise and use of complementary and alternative therapies can mitigate menopausal symptoms and improve the quality of life (5). Complementary and alternative therapy is one of the treatment methods that is particular among postmenopausal women (6). One of the common methods of complementary medicine is herbal therapy. Phytoestrogens are plant compounds with estrogenic activity that are used specifically to improve menopausal symptoms in postmenopausal women (7). G. glabra is a phytoestrogen that has multiple properties, such as impact on sleep disorders, fatigue, depression, hot flashes and treatment of gastric intestinal disorders caused by menopause (8). Also, due to the estrogenic properties in the roots of this plant, decreased symptoms of menopause and an increase in the physical and mental health of postmenopausal women are observed (9). Nevertheless, some believe that, although semi estrogen properties of G. glabra have been proved in the laboratory, clinical research is also needed (10). Exercise is another of the important therapeutic approaches for reducing the physical and psychological effects of menopause, and subsequently changing women's attitudes toward themselves. Exercise in addition to mental effect, through the increase of fibrinolysis system, improves menopausal symptoms such as: hot flashes, fatigue, and sex drive. It also has a positive effect on the treatment and prevention of diseases such as osteoporosis, arthritis and cardiovascular disease (11-12). Regular exercise helps menopausal women to maintain their weight, reduce their abdominal fat mass, and improve their sleep quality by $34 \%$ (13).

Although exercise as an effective method to mitigate and eliminate menopausal symptoms is essential, some experts believe exercise for all women at menopause cannot be effective for reasons that include osteoporosis, increased blood pressure and hot flashes (14). Many researchers support the use of complementary medicine and alternative methods (15), and since this plant has a positive effect on menopausal symptoms researchers reckon that perhaps this plant could be effective in mitigating menopause symptoms and changing postmenopausal women's attitudes.

Therefore, the researcher believes it might be possible that the combined use of exercise and $G$. glabra could lead to mitigation of menopausal symptoms and a change in the attitude of postmenopausal women towards themselves. Accordingly, the author did not find any research on combined effects of these two methods in the library, thus the present research was conducted to determine the clinical efficacy of combined use of G. glabra and aerobic exercise on the attitude of women in menopause state.

\section{Materials and methods}

This clinical trial pre-post-tests of four groups were conducted to determine the clinical effect of exercise training and $G$. glabra on the attitudes of postmenopausal women referred to Arak Aristotle clinic, between October 2013 and March 2014. According to an article by Yazdkhasti et al (3), with $95 \%$ probability and test power of $80 \%,=85 \%$ and a predicted $10 \%$ sample reduction, the least number of 
sample was estimated around 120 persons, minimum; $S=0.01$.

$\left(\beta=85 \%, \quad \alpha=0.05, \quad \mu_{1}=113.30 \pm 34.45\right.$, $\mu_{2}=138.35 \pm 17$ ).

In this study, after receiving permission from the Ethical Committee of Arak University of Medical Sciences, informed consent form was completed. Inclusion criteria were: 48-52 year- -old women who had passed at least one year and a maximum of three years since their last menstrual period, lack of chronic diseases such as diabetes, hypertension, no history of hypothyroidism and hyperthyroidism, no history of surgical removal of ovaries and uterus, having spouse, no history of depression and psychiatric disorders, being a nonsmoker, lack of the use of HRT (estrogen replacement therapy).The participants were excluded from the study if they were having physical and psychological diseases declared by themselves, and the incidence of adverse or disease events during the study, the new drug application by a physician, as well as musculoskeletal disorders such as fracture that could prevent the participant's ability to exercise.

120 eligible postmenopausal women were selected by convenience sampling method, and randomly divided into 4 groups using a table of random numbers. Each group consisted of 30 individuals. Group "A" received three tablets of G. glabra daily (manufactured by Razak Pharmaceutical Company, containing $380 \mathrm{mg}$ of G. glabra extract) in the morning, noon, evening before the meal (due to favorable digestive effects of the plants such as eliminating indigestion, flatulence, heartburn and constipation, according to the manufacturer's instructions) (16) for 4 weeks. In group "B" a regular program of aerobic exercise including walking, three sessions (even days) per week at 9 am, for a period of 4 weeks was undertaken. This means that each session included a 5 minute warm up, 30 min regular walking and 5 min cool down (17). In Group "C", at the same time, the use of G. glabra such as the first group and exercise program such as the second group, was conducted. In Group "D", or control group, no intervention was carried out, and only the relevant questionnaires were completed. Assurance was given to the control group that they could use each of the methods they preferred after the study. At the beginning and end of the four weeks after the intervention, subjects were given questionnaires to be completed by selfreport. The questionnaire included demographic questionnaire and postmenopausal attitude.

The questionnaire included 11 questions with Likert scale: agree, neutral, and disagree. The positive attitude in each question scored 3, neutral scored 2 and negative attitude scored 1 (the highest score was 33 and the lowest was 11). 1-24-5-6-9-11 questions were indicative of a negative attitude and scored 1, and questions 3-7-8-10 were indicative of positive attitude and scored 3. The "neutral" at all options scored 2. Given that women's attitudes about menopause are influenced by several factors such as age, number of pregnancies, hormonal status, socio-economic status, culture, education and geographical differences of each country, by a review of the native documents, the questionnaire was developed and given to ten nursing educators and three psychologists to comment on. Then, their opinions were imposed after consultation, and content validity was carried out. Eventually, data consistency was analyzed with Cronbach's alpha coefficient 0.86. Statistical tests, analysis of variance (ANOVA) and paired t-test with SPSS V.16 were used for analyzing the data.

\section{Results}

In each of the four groups in this study, 30 postmenopausal women were eligible for inclusion and none of them left the study. There was not a significant difference in terms of mean age, age at menopause, body mass index, and number of deceased 
and living children, education, occupation, and income level, before the intervention (Table 1). The results of paired t-test showed that, in the group A, B and C groups there was a statistically significant difference between the attitudes of postmenopausal women before and after the intervention, and with respect to the means (averages), the scores were higher after intervention (Table 2). Also, the result of ANOVA showed that, there was no statistically significant difference in the attitude of women between the four groups before the intervention, however, after the intervention there was significant difference $(\mathrm{P}=0.001)$. The result of follow-up LSD test regarding comparison of attitude score of postmenopausal women after treatment also showed the groups $\mathrm{A}$ and $\mathrm{C}$ with $(\mathrm{P}<0.002), \mathrm{B}$ and $\mathrm{C}$ with $(\mathrm{P}<0.032)$, group $\mathrm{D}$ and $\mathrm{C}$, $(\mathrm{P}$ $<0.001)$ had significant differences. Average attitude score showed that, in the group $\mathrm{C}$ the attitude scores were higher than the groups A, B and D (Table 2).

Table 1. Demographic characteristics of menopausal women in four groups (A, B, D and C groups, each containing 30 persons).

\begin{tabular}{lccccc}
\hline Characteristics & $\begin{array}{c}\text { Glycyrrhiza glabra } \\
\text { (Group A) }\end{array}$ & $\begin{array}{c}\text { Exercise } \\
\text { (Group B) }\end{array}$ & $\begin{array}{c}\text { Glycyrrhiza glabra and } \\
\text { exercise } \\
\text { (Group C) }\end{array}$ & $\begin{array}{c}\text { None } \\
\text { (Group D) }\end{array}$ & P value \\
\hline Age at time of study & $51.91 \pm 2.02$ & $51.82 \pm 1.76$ & $51.93 \pm 1.98$ & $51.92 \pm 1.65$ & 0.99 \\
Age at menopause & $49.62 \pm 1.09$ & $50.44 \pm 1.43$ & $50.05 \pm 1.16$ & $50.22 \pm 1.16$ & 0.04 \\
Body mass index & $24.91 \pm 20.06$ & $25.02 \pm 2.55$ & $25.06 \pm 2.20$ & $25.26 \pm 2.53$ & 0.95 \\
Number of living children & $4.23 \pm 1.73$ & $3.46 \pm 1.63$ & $0.64 \pm 1.52$ & $4.56 \pm 1.51$ & 0.08 \\
Number of dead children & $0.33 \pm 0.55$ & $0.4 \pm 0.56$ & $0.2 \pm 0.48$ & $0.166 \pm 0.46$ & 0.26 \\
\hline
\end{tabular}

Table 2. Comparison of the mean and standard deviation of attitude before and one month after the intervention in four groups.

\begin{tabular}{lccc}
\hline Groups & Before intervention & After intervention & P value \\
\hline Glycyrrhiza glabra & $21.1 \pm 2.63$ & $24.1 \pm 2.49$ & 0.0001 \\
Exercise & $20.63 \pm 2.70$ & $23.7 \pm 2.74$ & 0.0001 \\
Glycyrrhiza glabra and Exercise & $18.66 \pm 3.28$ & $24.3 \pm 6.67$ & 0.0001 \\
None & $21.1 \pm 3.44$ & $23.7 \pm 3.61$ & 0.062 \\
\hline
\end{tabular}

\section{Discussion}

This study aimed to determine the effect of G. glabra and regular aerobic exercise program (combined), on the women's attitudes toward menopause. The results suggest a positive effect of combined use of G. glabra and aerobic exercise program on improving women's attitudes toward menopause. Researcher found no study about the effect this plant on the attitudes of postmenopausal women. The study findings also confirmed Nahidi et al's study which concluded that, G. glabra can reduce the number of nocturnal hot flashes and increase the level of physical and mental health of postmenopausal women (18). The researcher believes that, the consumption of $G$. glabra decreases hot flashes which is a common and uncomfortable side effect of menopause, and consequently improves the physical and mental health of postmenopausal women, and this can improve women's attitudes toward menopause.

Amiripedan et al in a study titled, "Combined effect of Ginkobilo on the attitude of post postmenopausal women toward sex", concluded that, the use of phytoestrogens like Gingobilo plant leads to an improvement in women's sexual activities and attitude toward sex (20). In this study, another phytoestrogens plant (G. glabra) has been used, which was effective in improving women's attitudes toward menopause. Thus, although hormonal changes and problems after menopause are inevitable, the severity of 
the symptoms can be limited. Accepting menopause and having a positive attitude to cope with the effects of this period is very important.

The findings of this study showed that, regular physical exercise had a positive effect on the attitude of postmenopausal women. This is consistent with the results of Amin Shekarvey et al's study. Researchers claim that, regular physical activities along with walking have a positive effect on the quality of women's lives, therefore, it is suggested that programs be designed to encourage women to take part in a regular and focused walking exercise (21).

King et al in their study to evaluate the effect of regular physical activity on the well-being and quality of life of elderly people concluded that, regular physical activity can increase the quality of life and well-being of the elderly (22). Salesi et al in their study titled, "Effect of exercise and physical activity on happiness of postmenopausal women" concluded that, participation in exercise programs significantly affects the post-menopausal women's happiness level (23). Happiness can be defined as an indicator whereby people with a positive attitude assess the overall situation of their lives. Therefore, regular training programs can be useful for postmenopausal women, and this vulnerable group can use training programs to reduce the symptoms of menopause.

Richani et al in their study which examined the effect of exercise on psychological factors of stress in postmenopausal women concluded that, exercise can significantly reduce the stress level of postmenopausal women. They stated that, regular physical exercise can improve the quality of life of postmenopausal women (24) However, the results of Aiello et al's study titled, "Longterm effects of exercise interventions on the severity of menopausal symptoms" showed that exercise programs do not have a significant effect on menopausal symptoms in postmenopausal women (25). In the study, the type of exercise performed has not been described. Therefore, the researcher believes that, perhaps the type of exercise might have caused those results, or a suitable time for the exercise was not taken into consideration. The findings of present study suggest that, aerobic exercise along with taking G. glabra pills can have the greatest impact in improving women's attitudes toward menopause. With an extensive review of the literature, the author did not find any research regarding the effects of exercise programs and herbal therapy methods to control symptoms of menopause and improve women's attitudes. The researcher believes that, perhaps concurrent use of G. glabra and exercise may have complementary effects. Maybe the antioxidant quality of G. glabra reduces hot flashes, fatigue and mood swings of postmenopausal women, and regular exercise by helping to maintain a healthy weight, mentally changes the attitudes of postmenopausal women towards themselves. The researcher believes that further studies are needed to approve the effect of G. glabra along with exercise to improve the attitude of postmenopausal women. It must be mentioned that, the present study was conducted in one month's time, thus, future studies could be carried out in a longer period to examine the effect of $G$. glabra plant and aerobic exercise. Many factors can affect women's attitudes, particularly postmenopausal women, thus this study could not examine all factors. Future studies can be designed in such way to explore more confounding factors.

\section{Conclusion}

With regard to the findings of this study, the use of G. glabra in women who are not interested in harmonic medications or are allergic to them, as well as regular exercise programs as a safe and cost-effective method, can be suggested. 


\section{References}

1. Asgari P, Bahramnezhad F, Narenji F, Golitaleb M, Askari M. A clinical study of Glycyrrhizza glabra plant and exercise on the quality of life of menopausal woman. Chron Dis J. 2015; 3(2):5-15.

2. Uncu Y, Alper Z, Ozdemir H, Bilgel $\mathrm{N}$, Uncu G. The perception of menopause and hormone therapy among women in Turkey. Climacteric. 2007; 10(1):63-71.

3. Yazdkhasti M, Merghati E, Hosseini A. The Effect of Structured Educational Program by Support Group on Menopause Women's Quality of Life. Iran J Med Educat. 2012; 11(8):986-94.

4. Teede HJ, Lombard C, Deeks AA. Obesity, metabolic complications and the menopause: an opportunity for prevention. Climacteric. 2010; 13(3): 203-9.

5. Kumari M, Stafford M, Marmot M. The menopausal transition was associated in a prospective study with decreased health functioning in women who report menopausal symptoms. J Clin Epidemiol. 2005;58(3):719-27.

6. Chen L, Wang B, Chen I, Shao C. Use of Chinese herbal medicine among menopausal women in Taiwan. Int $\mathbf{J}$ Gynaecol Obstet. 2010:109(2):63-6.

7. Panay N, Rees M. Alternatives to hormone replacement therapy for management of menopause symptoms. Curr Obstet Gynecol. 2005; 15(2): 259-66.

8. Carlson F, Igelo M. Sense of coherence quality of life before coronary artery bypass surgery, longitudinal study. J Adv Nurs. 2000;31(6):1383-92.

9. Bera K. The effect of life style interventions on quality of life and patient satisfaction with health and health care. J Cardiovasc Nurs. 2003; 18(4):319-25.

10. Asgari $P$, Zand $S$, Narenji $F$, Bahramnezhad F, Mahmoudi M. The effect of glycurrhiza glabra on quality of life in postpausal women. Complement Med J.2015;2(15):114654.

11. Margaret S, Genevieve FD, Dan M. Physical Activity and Physical SelfConcept among Sedentary Adolescent Females an Intervention Study. Psycho Sport Exerc. 2008; 9(1):1-14.

12. Kama Z, Erkan S. Factors associated with menopausal symptoms and their relationship with the quality of life among Turkish women. Maturitas. 2007; 58(2):75-82.

13. Salehi K, Ehsanpour S, Zolfaghari B, Salehi Z, Honargoo M. [Effect of red clover Isoflavones extract on menopausal symptoms]. J Gorgan Uni Med Sci. 2013; 15(2):21-8. (Persian)

14. Stojanovska L, Apostolopoulos V, Polman R, Borkoles E. To exercise, or, not to exercise, during menopause and beyond. Maturitas. 2014; 77(4):318-23.

15. Chandwani KD, Heckler CE, Mohile SG, Mustian KM, Janelsins M, Peppone LJ, et al. Hot flashes severity, complementary and alternative medicine use, and self-rated health in women with breast cancer. Explore (NY). 2014; 10(4):241-7.

16. Menati L, Siahpoosh A, Tadayon M. A randomized double blind clinical trial of licorice on hot flash in postmenopausal women and comparison with hormone replacement therapy. Iran J Pharm Res. 2010; 9(2):157-67.

17. Tartibian B, Sharabiani S, Abbasi A. [Effect of Regular Aerobic Exercise on Vasomotor Symptoms (Hot Flashes) in Postmenopausal Women]. J Babol Uni Med Sci. 2009;11(4):36-41.(Persian)

18. Nahidi F, Zare E, Mojab F, Allavi Majd H. [The effect of Glycyrriza glabra on the number of night hot flashes postmenopausal women]. J Shahid Beheshti Uni Med Sci. 2010; 19(67):21-5. (Persian) 
19. Hajirahimkhan A, Charlotte S, Yang Y, Jeffrey RA, Shao-Nong C, Dejan N, et al. Evaluation of Estrogenic Activity of Licorice Species in Comparison with Hops Used in Botanicals for Menopausal Symptoms. Plos One. 2013; 8(7):1-11.

20. Amiri Pebdani M, Taavoni S, Haghani $H$. [The effect of herbal supplement of ginkgo biloba on attitude towaed menopausal woman to sexual reliations]. J Urmia Nurs Midwifery. 2013; 11(3):231-7. (Persian)

21. Amin Shekarvey F, Alhani F, Kazemnejad A, Vahdaninia M. [Relationship of physical activities with female quality of life]. Payesh. 2009; 4(4):407-13. (Persian)
22. King MB, Whiple Rh, Groman CA. Performance enhancment progect: improving physical performance in older persons. Arc Phs Med Rehabi. 2003; 83(12):1060-69.

23. Salesi M, Jookar B. The effect of exercise on menopausal women happiness. J Iran Geriatr. 2011; 6(20):7-14.

24. Sunsern R. Effect of exercise on stress in thai post menopause women. Health Care Women Int. 2002; 23(8):924-32.

25. Aiello EJ, Yasui Y, Tworoger SS, Ulrich CM, Irwin ML, Bowen D, et al. Effect of a yearlong, moderateintensity exercise intervention on the occurrence and severity of menopause symptoms in postmenopausal women. Menopause. 2004; 11(4):382-8. 